\title{
Youth, Education and the Ethos of Vulnerability in Uncertain Times
}

\author{
Babak Dadvand $^{1} \cdot$ Julie McLeod ${ }^{1}$
}

Published online: 21 October 2021

(c) The Author(s), under exclusive licence to Springer Nature Singapore Pte Ltd. 2021

\section{Editors' Introduction}

The term vulnerability has gained considerable traction in public and policy debates over the past decade or so. It is frequently used in relation to individuals and groups who are identified as 'at risk' and in need of interventions to prevent or ameliorate the experience and consequences of vulnerability. Young people in general and specific groups of young people in particular are increasingly positioned within discourses of vulnerability, their identities and prospects defined either by its presence or absence. Concurrently, there are widespread and growing social, political, economic and environmental uncertainties, coinciding with intensified efforts to regulate young people's conduct and aspirations through an array of policies and programs (Spohrer et al. 2018). In constructing young people simultaneously as the problem and the source of solutions, policy responses frequently look to the portals of education and training to minimise risk, manage uncertainty and protect the future.

This special issue draws on diverse conceptual and empirical approaches to interrogate the notion of 'vulnerable youth'. In doing so, the contributors consider multiple phenomenologies, ranging from discursive constructions of 'vulnerability' to young people as sense-making agents who read and respond to the material-historical conditions shaping their experiences in the present and their anticipated futures. As a populational and sociological category, 'youth' is presented as both a unifying category - as a temporal stage - and one structured by divisions and differences that also mediate the experiences of other stage-based cohorts. The papers share a focus on (1) how youth are rendered 'vulnerable' within educational, economic and political spheres of life and (2) how young people negotiate and respond to the social, material and discursive conditions that (re)produce risk and vulnerability for them.

Babak Dadvand

babak.dadvand@unimelb.edu.au

Julie McLeod

j.mcleod@unimelb.edu.au

1 Melbourne Graduate School of Education, The University of Melbourne, Melbourne, Australia 
Overall, this special issue seeks to offer critical diagnoses of the prevalence and effects of vulnerability discourses, to document the circumstances in which these arise, and to explore the capacities of young people themselves to navigate these framings and create alternative openings.

Questions about the (re)production of vulnerabilities prompt attention to wider considerations relating to individual agency, responsibility and reciprocity. Who comes to be regarded as 'vulnerable' is predicated on complex structural factors and discursive practices and rests upon normative conceptions about contemporary subjectivity and subjecthood. In recent years, these conceptions have been predominantly defined in economic terms with young people being encouraged to view and construct their lives and identities around what McNay (2009) calls the notion of 'self as an enterprise'. The entrepreneurial self is an intensely constructed and governed identity, a form of human capital tasked with improving and leveraging an individual's competitive positioning across all endeavours and venues including education, employment, health and family life (Brown 2015).

Teasing out taken-for-granted assumptions about the so-called vulnerable youth requires attention to a number of questions including distinguishing between how vulnerabilities (as a set of characteristics) are produced, inscribed and attached to certain groups, and the unstated normative identity against which certain youth cohorts are defined as vulnerable. This includes consideration of how structural disadvantages, discursive formulations and material-relational practices give meaning to, sustain and reproduce vulnerability and the opportunities that may exist for exposing and disrupting them. This special issue addresses these questions with a specific focus on young people's experiences in the domains of education and training. In doing so, the special issue brings together a body of youth studies scholarship that looks to better understand the lives of contemporary young people as one route into examining wider societal changes, based on the premise that the impact of such changes tends to be more pronounced among youth and to foreshadow wider ramifications (Harris et al. 2021).

\section{Why Vulnerability and Why Now?}

There is now a substantial body of scholarship critiquing the policy reach of the construct of vulnerability, often accompanied by robust interrogation of its conceptual limitations. Yet, such critiques have also faced obstacles in undoing or impeding the continuing rise and influence of vulnerability. The notion of vulnerability has a strong purchase on social imaginaries and has been remarkably effective in mobilising policy solutions and other forms of social regulation. Without pre-empting the analyses that are more fully developed in this special issue, we want to signal three key points to keep in mind as we track and trace the imprint of vulnerability discourses.

First, vulnerability joins a long line of discursive constructs and policy solutions that serve to individualise structural and social issues by repositioning them as problems that are aggravated - or ameliorated - by individual capacities or predispositions. Structural precarity might be recast or conflated as a problem of individual or 
group vulnerability. For example, in reference to work and educational pathways, some individuals, or categories of young people, may be characterised positively as enterprising, while others seen as lacking sufficient 'get up and go' to find a job or make the most of educational opportunities. Regardless of the merits or accuracy of such attributions, the overall effect is to responsibilise individuals. This not only diverts attention from the structural factors affecting youth pathways and employment, but it also underplays the larger, situated and historical contexts that have shaped the formation of dispositions and aspirations over time. That is, it tends to mystify such orientations or capacities as somehow an inherent part of the individual, an intrinsic weakness that might warrant a range of psy-based interventions, rather than, in Bourdieuian terms, as part of their habitus formed in interaction with the intersecting fields in which they are embedded (Bourdieu 1977).

Second, vulnerability can be fruitfully understood as part of a network of 'kindred concepts' (e.g. McLeod and Wright 2020), many drawing on psy-expertise to diagnose and solve both individual and social problems, with resilience, wellbeing, positive education and mindfulness some of the more prominent ones in the field of education. Somers (2008) has convincingly argued for seeing such concepts as 'relational - that is, they exist not as autonomous categories but relational patterns' (p3). This is not to suggest that all the connected concepts are fully aligned - there may well be tensions and contradictions. The analytic focus, however, is on how they interlock, and on how the historically framed and shifting 'relational patterns' shape ways of seeing and doing. Vulnerability, for example, can be seen to derive its currency in part through its relation to the policy and program machinery of 'resilience' which is both an antidote to vulnerability and a positively inflected attribute as well as drawing from a similar body of psy-expertise and ways of framing the individual.

Third, the prominence given to discourses of vulnerability coincides with growing attention to what Lauren Berlant has influentially characterised as "public feelings'; that is, to recognition of how emotions, once thought of as a private or personal experience, are actually integral to public life in how, for example, they 'influence politics and notions of social belonging and intimacy' (Barnard Center for Research on Women 2012). Without diminishing the regulatory effects of vulnerability discourses as noted above, we see the focus on public feelings as a reminder of the possibilities for attending to more hopeful dimensions of vulnerability. While vulnerability can register as weakness or a quasi-permanent state of being at-risk, it can also evoke expressions of tenderness and empathy, of being open to others, pointing to a common and positive dimension of human experience (Beckett 2006). Framing vulnerability as an ambiguous emotion is important; we suggest in seeking to understand how it operates in the realm of 'public feelings' and the ways in which it might be mobilised for a more relational and caring politics.

\section{Contributions to the Special Issue}

Contributions in this special issue address, in varied ways, some of these issues by interrogating the notions of vulnerable and at-risk youth. The contributors offer fresh perspectives on how multiple and often intersecting social, cultural, 
historical, material and discursive forces can be implicated in the production of vulnerability for young people, who constitute a diverse and non-homogeneous category (Dadvand 2020). The papers utilise methodological approaches that start from the lived experiences of youth within different contexts and faced with enduring and emerging forms of marginality. Utilising a rich array of structural, critical, feminist and post-structural approaches, the papers make visible the practices and relationships impacting young people's lives. In doing so, they advance existing scholarship on youth vulnerability not only by identifying 'the problem', but also by providing practical offerings informed by the often-marginal views and voices of youth as to how the conditions of vulnerability can be mitigated and/or disrupted.

Portals of education and training have been traditionally used as sites for 'risk management' and preparing young people for the social, economic and political requirements of life. Government policies and programs in these areas amount to what Foucault (1991) calls 'technologies of governance' aimed at producing subjects with a desired set of attributes, values and dispositions. Brunila, Vainio and Toiviainen study in this special issue shows how youth education, as an emblematic manifestation of an alliance between therapisation and neoliberalism, has altered the state-citizen relationship within the Nordic therapeutic welfare state. Predicated on the notion of psycho-emotionally vulnerable youth, government programs tend to psychologise wider social and structural problems. The emphasis of such programs in Finland, as the authors demonstrate, is building qualities such as resilience, selfresponsibility, competitiveness and entrepreneurialism.

The range and diversity of young people's experiences is captured by other contributors to the special issue. Writing in the backdrop of increasing anxieties that mark the temporal and spatial horizon of youth in the UK, Australia and France, Black and Walsh draw upon accounts from university students to examine how this cohort constructs and narrates their lives in present and for a future than remains ever more uncertain and unknowable. While university students may not fit neatly into the category of 'vulnerable youth', they experience the conditions of vulnerability in their present social lives and anticipated future. The authors engage with accounts from young people to demonstrate a common sense of disillusionment with the promise of higher education for more secure employment, while utilising strategies to navigate uncertainty towards their desired futures.

Dadvand's paper examines how young people can be rendered vulnerable within the institutional settings of schools. Using data collected from an alternative education program in a secondary school in the state of Victoria, Australia, the paper addresses the extent to which alternative educational arrangements can contribute to effective re-engagement opportunities for the so-called 'at risk' youth. Conceptualising vulnerability through a Butlerian lens, the paper shows how performativitydriven practices of schools have narrowed the parameters of recognition for young people who have more complex needs and circumstances. Highlighting the limits of empathy as a basis for re-engagement initiatives, Dadvand further argues that a focus on building affective solidarity can provide a politicised impetus for change by interrogating narrow frameworks of recognition and help build solidarity with 'the other' to whom our relationships remain incomplete. 
Neoliberal reform agendas also provide the backdrop to the discussion of government initiatives in the paper by Mäkelä, Ikävalko and Brunila. Studying the outreach youth activities offered to 'at risk' young people via the Finish youth support systems, the authors highlight the subjectivation power of such programs. The overarching aims of these programs are to shape young people's subjectivities as adaptable, yet psycho-emotionally vulnerable, subjects in need of intervention and management within a cycle of indebtedness and poverty that characterises the modern neoliberal logic of competition and capital accumulation. The authors further highlight the importance of youth agency in the face of policy and programmatic interventions by showing how young people can refuse to adapt into neoliberal governmentality and imagine different futures for themselves.

te Riele and Shelley's article provides further insights into how vulnerability can help provide a pre-condition for resistance and agency. Defining vulnerability as a product of specific social and historical relations, the authors interrogate narrow binary categories that assign risk to specific groups and demonstrate the potential of 'vulnerability' for cultivating agency. The context for discussions in the paper is a local initiative aimed at tackling family violence and bringing about generational change by supporting young rural women of secondary school age in a low socioeconomic, regional community in Australia. This program, as te Riele and Shelley demonstrate, contributes via a strengths-based approach that prioritises connections with place and identity, recognises aspirations and builds capacity. The overarching aims are to enable young people to narrate and live their lives in their own terms and act as active agents of change within their own communities.

Finally, writing in the backdrop of the highly marketised education system in Australia, Zipin, Brennan and Trevorrow map and trace how elements within socialstructural as well as policy contexts encourage schools to differentiate among young people in socioeconomically marginalised communities. The authors draw on student voice data collected from a group of 'high achievers' from marginalised backgrounds to explore how performative priorities of schools aggravate social and structural vulnerabilities for these students as well as for their peers who are identified as low or non-achievers. To foster opportunities for inclusion, voice and participation, the authors call for building alliances between educators, students and their local communities. Integral to such an alliance is an ethics-based curriculum that recognises the diversity of students' lived experiences and offers alienated youth opportunities to be heard and taken into account.

\section{References}

Barnard Center for Research on Women (2012) Public feelings salon with Lauren Berlant. Retrieved from https://bcrw.barnard.edu/videos/public-feelings-salon-with-lauren-berlant/. Accessed 5 Oct 2021

Beckett A (2006) Citizenship and vulnerability: disability and issues of social engagement. Palgrave Macmillan, Basingstoke

Bourdieu P (1977) Outline of a theory of practice (R. Nice, Trans.). Cambridge University Press, Cambridge 
Brown W (2015) Undoing the demos: neoliberalism's stealth revolution. Zone Books, New York

Dadvand B (2020) Civics and Citizenship education in Australia: the importance of a social justice agenda. In Peterson A, Stahl G, Soong H (eds) The Palgrave Handbook of Citizenship and Education. Palgrave Macmillan, Cham, pp 435-447

Foucault M (1991) The Foucault effect: studies in governmentality. University of Chicago Press, Chicago

Harris A, Cuervo H, Wyn J (2021) Thinking about belonging in youth studies. Springer, Switzerland

McLeod J, Wright K (2020) Critical policy studies and historical sociology of concepts: Wellbeing and mindfulness in education. In: Leahy D, Fitzpatrick K, Wright J (eds) Social Theory and Health Education: Forging New Insights in Research. Routledge, London, pp 93-103

McNay L (2009) Self as enterprise: dilemmas of control and resistance in Foucault's The Birth of Biopolitics. Theory Cult Soc 26(6):55-77

Somers M (2008) Genealogies of citizenship: markets, statelessness, and right to have rights. Cambridge University Press, New York

Spohrer K, Stahl G, Bowers-Brown T (2018) Constituting neoliberal subjects?'Aspiration’as technology of government in UK policy discourse. J Educ Policy 33(3):327-342 